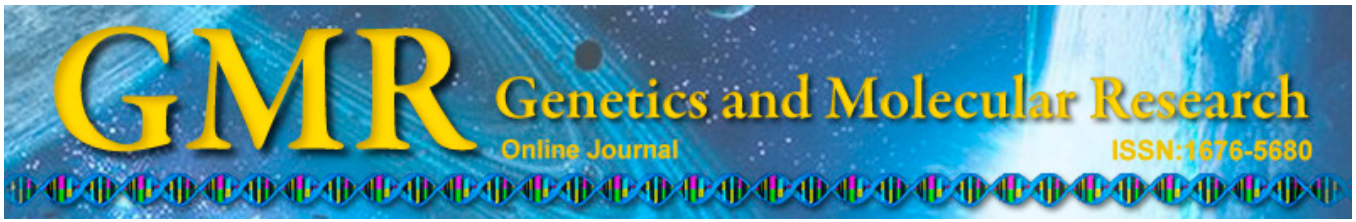

\title{
Cloning flanking sequence by single-primer PCR in transgenic plants
}

\author{
J. Ma ${ }^{1}$, Y.P. Wang ${ }^{1}$, S. Ren ${ }^{2}$, Z. Zhang ${ }^{1}$, S. Lu ${ }^{1}$ and P.W. Wang ${ }^{1}$ \\ ${ }^{1}$ Biotechnology Center of Jilin Agricultural University, Changchun, \\ Jilin Province, China \\ ${ }^{2}$ Jilin Provincial Center for Instruction of Undergraduates, Changchun, \\ Jilin Province, China \\ Corresponding author: P.W. Wang \\ E-mail: davidmedsci@sina.com
}

Genet. Mol. Res. 13 (4): 8403-8410 (2014)

Received August 14, 2013

Accepted March 11, 2014

Published October 20, 2014

DOI http://dx.doi.org/10.4238/2014.October.20.16

\begin{abstract}
The insertion position of exogenous genes in plant genomes is usually identified by adapter ligation-mediated polymerase chain reaction (PCR), thermal asymmetric interlaced PCR, and restriction site extension PCR in transgenic plant research. However, these methods have various limitations, such as the complexity of designing primers and time-consuming and multiple-step procedures. The goal of this study was to establish an easier, more rapid, and more accurate method to clone flanking sequence using single-primer PCR in transgenic plants. Unknown flanking genome sequences in transgenic plants, including those in tobacco, soybean, rice, and maize, were cloned using the single-primer PCR method established in this study, with the Bar gene as the anchor gene. The primer 1 (P1), P2, and P3 PCRs obtained 4 sequences, and the completely correct flanking sequence of 508 bp that was obtained in the P3 PCR was verified by sequencing analysis. The single-primer PCR is more rapid and accurate than conventional methods, justifying its application widely in cloning flanking sequences in transgenic plants.
\end{abstract}

Key words: Single-primer PCR; Unknown flanking sequences; Transgenic plants 


\section{INTRODUCTION}

The insertion positions of exogenous genes in targeted plant genomes is usually identified by adapter ligation-mediated polymerase chain reaction (PCR) (Jones and Winistorfer, 1992), thermal asymmetric interlaced PCR (TAIL PCR) (Song et al., 2005; Liu and Chen, 2007), and restriction site extension PCR (RSE PCR) (Ji and Braam, 2010) in transgenic plant research. TAIL PCR, one of the most widely used methods, requires 3 anchor primers and 4-8 degenerate and random primers, takes $8-10 \mathrm{~h}$ to complete, and involves complex procedures to obtain a known flanking sequence through 3 rounds of asymmetric interlaced PCR. In contrast, to obtain a flanking sequence by the RSE PCR method, the genome has to be digested first by enzymes and then subjected to various procedures. There are various limitations to these methods, such as the complexity of designing primers and the need for time-consuming and multiple-step procedures. Therefore, easy, rapid, and accurate methods are needed to clone flanking sequences. It is possible to combine the degenerate and random primers into a single primer to simplify the primer design and to improve the efficiency of cloning unknown flanking sequences.

In this study, unknown flanking genome sequences in transgenic plants, including tobacco, soybean, rice, and maize, were cloned using single-primer PCR with the Bar gene as the anchor gene.

\section{MATERIAL AND METHODS}

\section{Materials}

Genomic DNA from Bar-transfected plants including tobacco, soybean, rice, and maize were used in this study. The KOD DNA polymerase kit with $10 \mathrm{mM} \mathrm{dNTP}$, and 10X PCR buffer containing $12 \mathrm{mM} \mathrm{MgCl}, 100 \mathrm{mM} \mathrm{KCl}_{2}, 60 \mathrm{mM}\left(\mathrm{NH}_{4}\right)_{2} \mathrm{SO}_{4}, 100 \mu \mathrm{L} / \mathrm{mL}$ bovine serum albumin, 1.2 M Tris- $\mathrm{HCl}$, and 1\% TritonX-100 was purchased from Genview (USA). Agarose, Tris, boric acid, and ethylenediaminetetraacetic acid (EDTA) were purchased from AMRESCO (USA). The Genomic DNA Extraction Kit and DNA Marker were purchased from TaKaRa (Dalian, China).

\section{Primers}

Five single primers specific for the Bar gene were designed as previously reported (NCBI database GenBank: KF206150.1) with some modifications, and the sequences are listed in Table 1.

Table 1. Primers.
\begin{tabular}{llcc}
\hline Primer & Sequences (5'-3') & Primer length (bp) & Distance from the left border (bp) \\
\hline P1 & ACGCGGGCCCCTGGAA & 16 & 602 \\
P2 & TGGCATGACGTGGGTT & 16 & 348 \\
P3 & GCTTCAAGCACGGGAA & 16 & 365 \\
P4 & GTCATCGGGCTGCCCAA & 17 & 446 \\
P5 & GACTTCAGCCTGCCGGT & 17 & 320 \\
\hline
\end{tabular}


All primers that were designed in this study served not only as anchor primers but also as random primers. All of the primers including P1, P2, P3, P4, and P5 were improved and performed better than those reported previously (Song et al., 2005; Liang et al., 2010; Ma et al., 2011a,b; Zhang et al., 2012), with characteristics consistent with those of single primers. When designing the P1 single primer based on the Bar gene with the vector pCAMBIA3300, we used the degenerate random primer sequence reported previously (Song et al., 2005; Liu and Chen, 2007; Ji and Braam, 2010) as a guide. The degenerate random primer contained the degenerate random sequence 5'-HNHNNNGGAA-3' (where $\mathrm{N}=\mathrm{A} / \mathrm{G} / \mathrm{C} / \mathrm{T}$ and $\mathrm{H}=\mathrm{G} / \mathrm{C} / \mathrm{A}$ ). The sequences of 5'-GGAA-3' in the Bar gene and the degenerate random primer were first located. Accordingly, three consecutive Ns toward the 5'-terminal orientation in the degenerate random primer were $\mathrm{T}, \mathrm{C}$, and $\mathrm{C}$ in the Bar gene, respectively. Then, $\mathrm{H}$ was $\mathrm{C}, \mathrm{N}$ was $\mathrm{C}, \mathrm{H}$ was G, and six bases were 5'-ACGCGG-3' toward the 5'-terminus. Thus, the single-primer P1 was 5'-ACGCGGGCCCCTGGAA-3'. The relationship between the P1 single primer and the previous degenerate random primer was shown below.

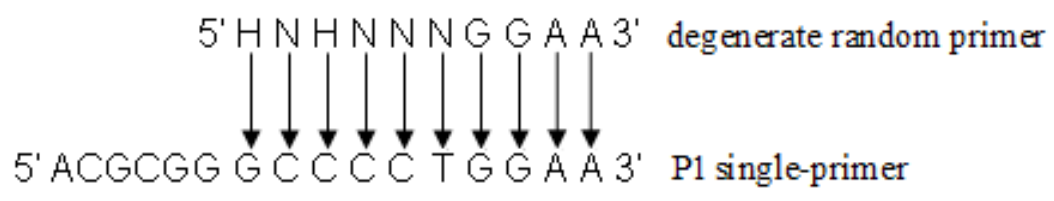

The same method was used to design primers P2-P5. Positions of each primer in the vector were shown in Figure 1. The above single primers could pair well with the Bar gene; thus, they could serve as the anchor primers. At the same time, they could serve as the random primers because the primer design considered the random primer strategy.

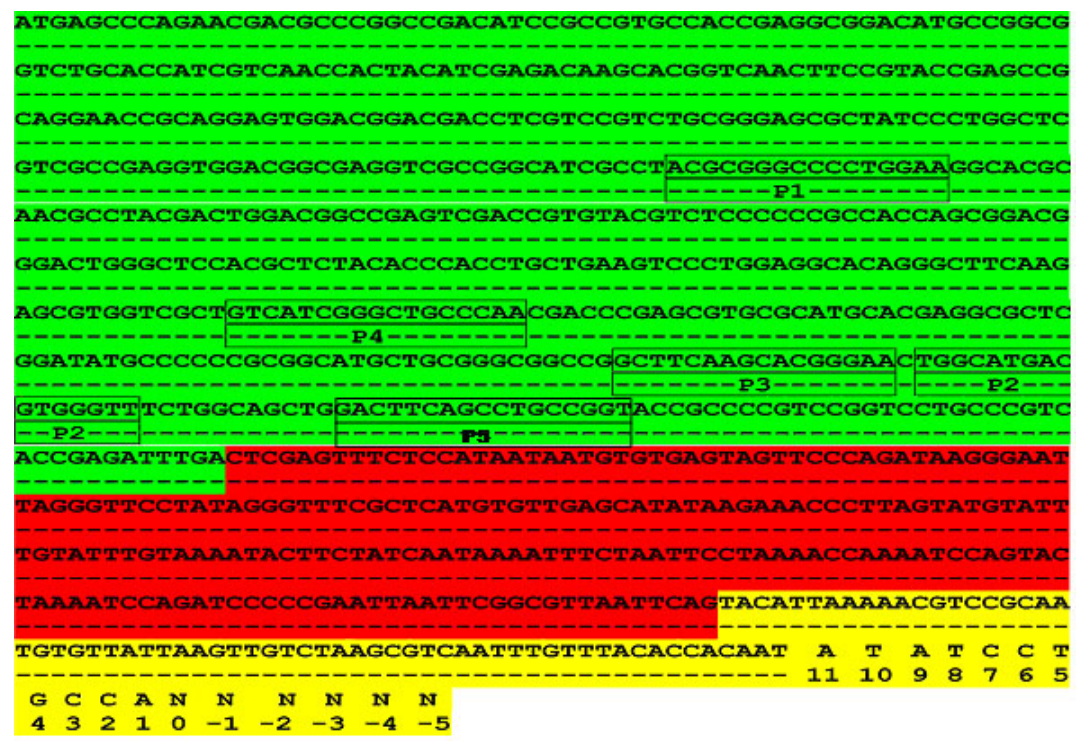

Figure 1. Positions of each primer in the T-DNA vector. Green color indicates the bar gene; red color is the 35SpolyA; yellow color is the left border of the vector. 


\section{Detection of the transgenic plants}

Transgenic plants were identified as reported previously (Lu et al., 2011) using the QuickStix Kit 060591 (EnviroLogix Inc., USA) according to manufacturer directions. Briefly, $0.2 \mathrm{~g}$ leaves from transgenic plants was collected in $1.5-\mathrm{mL}$ tubes. One hundred microliters of extraction buffer was added to the tubes, and the samples were ground for $5 \mathrm{~min}$. Then, the test strips were incubated in the ground samples for $10 \mathrm{~min}$ to examine whether positive bands corresponding to the Bar product appeared to assess the expression of Bar in each transgenic plant.

\section{PCR}

PCR was conducted as reported previously (Jones and Winistorfer, 1992; Liu and Whittier, 1995; Liu and Chen, 2007; Ma et al., 2012). Total DNA of transgenic maize was extracted from plant leaves using the Universal Genomic DNA Extraction Kit (version 3.0; $\mathrm{TaKaRa})$ according to manufacturer instructions. The reaction mixture ( $50 \mu \mathrm{L}$ total) for singleprimer amplification with P1 contained $5.0 \mu \mathrm{L} 10 \mathrm{X}$ buffer, $1.0 \mu \mathrm{L} 10 \mathrm{mM}$ dNTPs, $1.0 \mu \mathrm{L} 20$ $\mu \mathrm{M}$ P1 primer, $1.0 \mu \mathrm{L}$ genomic DNA template $(<1 \mu \mathrm{g}), 1.0 \mu \mathrm{L}$ KOD DNA Polymerase (2.5 U/ $\mu \mathrm{L}$ ), and $32 \mu \mathrm{L} \mathrm{ddH_{2 }}$ O. The PCR was conducted using the following conditions: $98^{\circ} \mathrm{C}, 60 \mathrm{~s} ; 5$ cycles of $98^{\circ} \mathrm{C}, 30 \mathrm{~s}$ and $45^{\circ} \mathrm{C}, 30 \mathrm{~s} ; 74^{\circ} \mathrm{C}, 120 \mathrm{~s} ; 5$ cycles of $98^{\circ} \mathrm{C}, 30 \mathrm{~s}$ and $54^{\circ} \mathrm{C}, 30 \mathrm{~s}$; and $74^{\circ} \mathrm{C}, 120 \mathrm{~s}$. The reaction mixture and cycling conditions for single-primer amplification of P2, P3, P4, and P5 were the same as those for the PCR with P1 as the single primer.

\section{Agarose gel electrophoresis and purification of PCR products}

The PCR products of reactions with $\mathrm{P} 1, \mathrm{P} 2, \mathrm{P} 3, \mathrm{P} 4$, and $\mathrm{P} 5$ as the single primers were resolved by electrophoresis on $0.8 \%$ agarose gels, and bands of lengths exceeding 602,348 , 365,446 , and $320 \mathrm{bp}$, respectively, were recovered routinely (Jones and Winistorfer, 1992).

\section{Sequencing of PCR products}

PCR products were recovered and sequenced routinely, which was followed by Basic Local Alignment Search Tool analysis with published homologous sequences of flanking sequences of the Bar gene in the National Center for Biotechnology Information (NCBI) database (http://www.ncbi.nlm.nih.gov/nuccore/).

\section{RESULTS}

\section{Detection of the transgenic plants}

Based on the characteristics of random and degenerate primers in previous studies, it has been proposed that a single primer may serve not only as a random primer but also as a degenerate primer (Ma et al., 2011a,b, 2012). Thus, the single-primer PCR method was tested in this investigation.

In order to clone flanking sequence by single-primer PCR amplification in transgenic plants, including tobacco, soybean, rice, and maize, transgenic plants were first identified using Quickstix test strips. The test indicated that the Bar gene was integrated successfully into the genome of the transgenic plants and was expressed very well in the plants (data not shown). 


\section{Single-primer PCR in transgenic maize}

To establish and identify an easy, rapid, and accurate method to clone flanking sequences by single-primer PCR, samples of the transgenic plants identified above were collected and subjected to single-primer PCR analysis with P1, P2, P3, P4, and P5 as primers. The PCR products were resolved using agarose gel electrophoresis. As shown in Figure 2, the P1 and P2 single-primer PCRs obtained the A and B bands of the Bar gene in the transgenic maize, respectively. The $\mathrm{C}$ and $\mathrm{D}$ bands were obtained in the $\mathrm{P} 3$ single-primer PCRs, and the P4 and P5 PCRs did not obtain obvious bands.

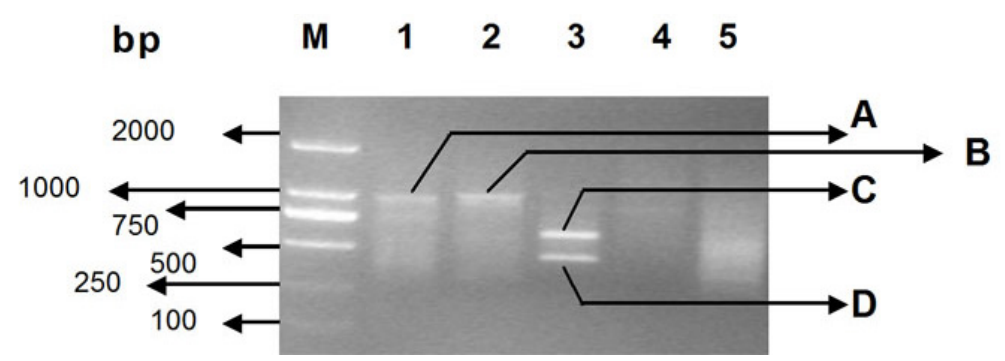

Figure 2. Single-primer PCR results in transgenic maize. Lane $M=$ DL2000 molecular weight marker; lanes 1-5 = PCRs with P1, P2, P3, P4, and P5 as single-primers, respectively. Bands A-D = 1000, 1100, 508, 490 bp.

\section{Sequencing results of PCR products from transgenic maize}

Although PCR products were obtained with the single-primer PCR method in this study, the sequences of PCR products were unknown and needed further analysis. To test the efficiency of the single-primer PCR method, PCR products of transgenic maize were subjected to agarose gel electrophoresis and recovered. The recovered PCR products were then subjected to sequencing analysis. Inevitably, the PCRs (P1-A, P2-B, P3-C/D; Figure 2) that were obtained in the single-primer $\mathrm{PCR}$ reactions with $\mathrm{P} 1, \mathrm{P} 2$, and $\mathrm{P} 3$ as primers mismatched partially and, like the double-primer PCR, the obtained flanking sequences were not completely correct. Only a 508-bp band (Figure 2, P3-C) was the correct flanking sequence that was verified by sequencing analysis (Figure 3).

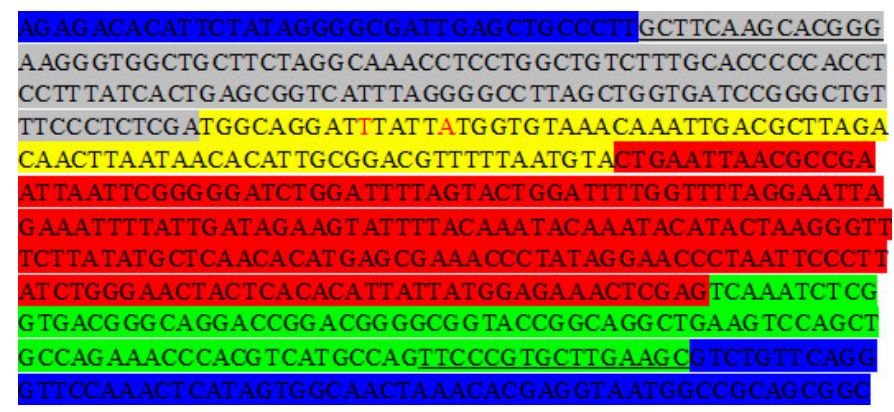

Figure 3. Sequencing results of band $\mathrm{C}$ in the PCR with $\mathrm{P} 3$ as the single-primer in transgenic maize. Sequences corresponding to the T vector pEASY-Blunt Simple cloning vector (blue), the Bar gene (green), 35S polyA (red), the left border of the expression vector (yellow) (the bases shown in red represent the two mutated bases), and the flanking sequence (gray) are shown. 


\section{Sequencing results of PCR products from transgenic tobacco, soybean, and rice}

To further address the utility of the single-primer PCR system, PCR products from transgenic plants, such as tobacco, soybean, and rice, were also subjected to sequence analysis. The sequencing results of band C with P3, P5, and P2 as the single primer are shown in Figures 4, 5, and 6, respectively. The sequence of the flanking sequence of soybean was homologous with an entry in the NCBI database (NM_001250170.1), suggesting that it was successfully cloned in this study with the single-primer PCR method.

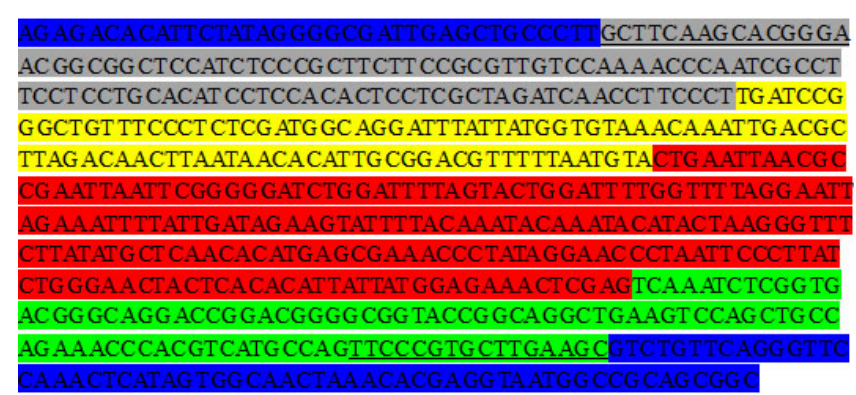

Figure 4. Sequencing result of band $\mathrm{C}$ with $\mathrm{P} 3$ as the single-primer in transgenic tobacco. Sequences corresponding to the T vector pEASY-Blunt Simple cloning vector (blue), the Bar gene (green), 35S polyA (red), the left border of the expression vector (yellow), and the flanking sequence (gray) are shown.

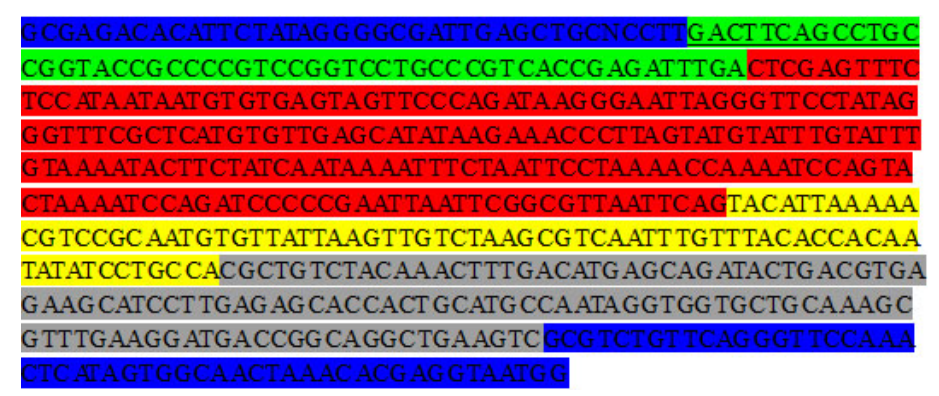

Figure 5. Sequencing result of band $C$ in the PCR with P5 as the single-primer in transgenic soybean. Sequences corresponding to the T vector pEASY-Blunt Simple cloning vector (blue), the Bar gene (green), 35S polyA(red), the left border of the expression vector (yellow), and the flanking sequence (gray) are shown.

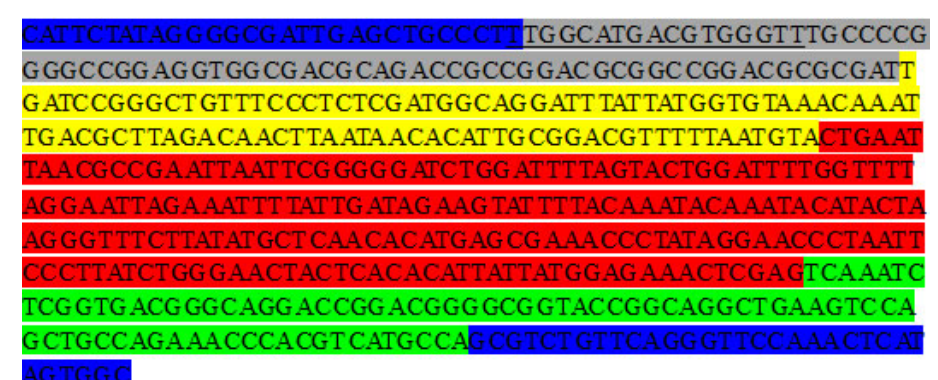

Figure 6. Sequencing result of band $\mathrm{C}$ with $\mathrm{P} 2$ as the single-primer in transgenic rice. Sequences corresponding to the T vector, pEASY-Blunt Simple cloning vector (blue), the Bar gene (green), 35S polyA (red), the left border of the expression vector (mustard), and the flanking sequence (gray) are shown. 


\section{DISCUSSION}

In this study, unknown flanking genomic sequences in transgenic plants, including those in tobacco, soybean, rice, and maize, were successfully cloned using single-primer PCR with the Bar gene as the anchor gene.

The methods that are currently used to identify the insertion positions of exogenous genes in plant genomes have various limitations (Liu et al., 1995; Liu and Whittier, 1995; Kim et al., 2004; Song et al., 2005; Liu and Chen, 2007; Liang et al., 2010). There is an urgent need for easier, quicker, and more accurate methods to clone the transgenic flanking sequences (Antal et al., 2004). In this study, we used the single-primer PCR method to successfully clone the flanking sequences in many transgenic plants, including maize, tobacco, soybean, and rice.

One of the most important innovations in this study was that the single primer served not only as a degenerate primer but also as a random primer, suggesting that it was a novel strategy for primer design that was applicable to the cloning of the transgenic flanking sequences. However, not all the single primers were successful in cloning new flanking sequences in transgenic plants. For example, the P4 and P5 primers did not yield satisfying PCR products. Furthermore, not all PCR products that were generated in our system included the unknown flanking sequences, such as bands $\mathrm{A}, \mathrm{B}$, and $\mathrm{D}$. Therefore, these data indicated that the single-primer PCR system still needs to be improved and enhanced.

In conclusion, the single-primer PCR method is suitable to clone flanking sequences. Further studies are needed to optimize this method for efficient cloning of transgenic flanking sequences.

\section{ACKNOWLEDGMENTS}

Research supported by grants from the National Natural Science Foundation of China (\#31171568), the Young Scientists Foundation of JILIN Province in China (\#20100145), and funds from the Chunmiao Talent Program for Scientific Research in Universities of the JILIN Province of China.

\section{REFERENCES}

Antal Z, Rascle C, Fevre M and Bruel C (2004). Single oligonucleotide nested PCR: a rapid method for the isolation of genes and their flanking regions from expressed sequence tags. Curr. Genet. 46: 240-246.

Ji J and Braam J (2010). Restriction site extension PCR: a novel method for high-throughput characterization of tagged DNA fragments and genome walking. PLoS One 5: e10577.

Jones DH and Winistorfer SC (1992). Sequence specific generation of a DNA panhandle permits PCR amplification of unknown flanking DNA. Nucleic Acids Res. 20: 595-600.

Kim YJ, Kwak CI, Gu YY, Hwang IT, et al. (2004). Annealing control primer system for identification of differentially expressed genes on agarose gels. Biotechniques 36: 424-426, 428, 430.

Liang CZ, Zhang R, Sun GQ, Meng ZG, et al. (2010). Cloning of stress-related transcription factors gene from cotton by optimized TAIL-PCR. Cott. Sci. 22: 195-201.

Liu YG and Whittier RF (1995). Thermal asymmetric interlaced PCR: automatable amplification and sequencing of insert end fragments from P1 and YAC clones for chromosome walking. Genomics 25: 674-681.

Liu YG and Chen Y (2007). High-efficiency thermal asymmetric interlaced PCR for amplification of unknown flanking sequences. Biotechniques 43: 649-650, 652, 654.

Liu YG, Mitsukawa N, Oosumi T and Whittier RF (1995). Efficient isolation and mapping of Arabidopsis thaliana T-DNA insert junctions by thermal asymmetric interlaced PCR. Plant J. 8: 457-463. 
Lu T, Li HY, Zhang JQ, Hu XN, et al. (2011). Acquisition and identification of transgenic soybean using bar as a selective agent. Soybean Sci. 30: 895-900.

Ma J, Wang PW, Yao D, Wang YP, et al. (2011a). Single-primer PCR correction: a strategy for false-positive exclusion. Genet. Mol. Res. 10: 150-159.

Ma J, Guan SC, Yao D, Wei YF, et al. (2011b). Problems with and a system to eliminate single-primer PCR product contamination in simple sequence repeat molecular marker-assisted selection in soybean. Genet. Mol. Res. 10: 16591668.

Ma J, Guan SC, Zhang Z and Wang PW (2012). Single- and double-SSR primer combined analyses in rice. Genet. Mol. Res. 11: 1032-1038.

Song DF, Han N, Bian HW and Zhu MY (2005). Analysis of cbfl flanking sequences in transgenic tobacco by TAIL-PCR. Acta Agron. Sin. 31: 1377-1379.

Zhang X, Zhang R, Sun G, Shi J, et al. (2012). High efficiency genome walking method for flanking sequences of cotton mitochondrial double-copy atpA gene based on optimized inverse PCR and TAIL-PCR. Sheng Wu Gong Cheng Xue Bao 28: 104-115. 